\title{
Correction to: Isolation and Analysis of Bacterial Ribosomes Through Sucrose Gradient Ultracentrifugation
}

\author{
Ricardo F. dos Santos, Cátia Bárria, Cecília M. Arraiano, \\ and José M. Andrade
}

Correction to:

Chapter 19 in: Tilman Heise (ed.), RNA Chaperones: Methods and Protocols, Methods in Molecular Biology, vol. 2106, https://doi.org/10.1007/978-1-0716-0231-7_19

This chapter was inadvertently published without including the author Cátia Bárria. The correct authorship for this chapter has been corrected to Ricardo F. dos Santos, Cátia Bárria, Cecília M. Arraiano, and José M. Andrade. The sentence before the final sentence in the acknowledgement section has been corrected to "R.F.dS. is recipient of an FCT Doctoral fellowship (PD/BD/105733/2014) and Cátia Bárria is recipient of a FCT Post-doctoral grant PTDC/BIA-BQM/28479/2017)".

The updated online version of this chapter can be found at https://doi.org/10.1007/978-1-0716-0231-7_19 